\title{
ESPACIALIZAÇÃO DOS CASOS DE SARS-COV-2 NA REDE URBANA DE MATO GROSSO DO SUL: UMA ANÁLISE DA 11ª À 18 ${ }^{\text {a }}$ SEMANA EPIDEMIOLÓGICA DE 2020
}

\section{SPATIALIZATION OF SARS-COV-2 CASES IN THE URBAN NETWORK OF MATO GROSSO DO SUL: ANALYSIS FROM 11th TO 18th EPIDEMIOLOGICAL WEEK OF 2020}

\author{
Adeir Archanjo da Mota \\ Doutor, Prof. do Programa de Pós-graduação em Geografia \\ Universidade Federal da Grande Dourado \\ adeirmota@ufgd.edu.br \\ Maria José Martinelli Silva Calixto \\ Doutora, Profa. do Programa de Pós-graduação em Geografia \\ Universidade Federal da Grande Dourado \\ mjmartinelli@yahoo.com.br
}

\begin{abstract}
RESUMO
A pandemia da COVID-19, declarada pela Organização Mundial da Saúde, é uma emergência de saúde pública de importância internacional. Os agravos à saúde humana pelo vírus SARS-CoV-2, e os impactos socioambientais e econômicos dele decorrentes, exigem respostas imediatas e articuladas, envolvendo estudos de diferentes áreas do conhecimento. Nesta perspectiva, este artigo é resultado de um estudo em desenvolvimento, de caráter exploratório, descritivo e analítico, que objetiva mapear a distribuição espaço-temporal dos casos confirmados e dos óbitos registrados no estado de Mato Grosso do Sul. Da mesma forma, visa identificar, na rede urbana, a associação espacial entre os níveis de centralidade e os 280 casos positivos. Considerando sete semanas epidemiológicas, pode-se afirmar que, de forma geral e preliminarmente, o contágio evolui dos centros urbanos de maiores níveis de centralidade para os de menores níveis. Por outro lado, as interações espaciais heterárquicas também contribuem para compreender o início do contágio em centros de menor nível hierárquico. Ressalta-se que os resultados podem contribuir com a vigilância em saúde estadual, oferecendo subsídios para a priorização de locais para ações, para o monitoramento e para estudos que possam identificar riscos e vulnerabilidades socioambientais.
\end{abstract}

Palavras chave: Geografia da Saúde. Rede Urbana. COVID-19. Mato Grosso do Sul.

\begin{abstract}
The COVID-19 pandemic, declared by the World Health Organization, is a public health emergency of international importance. The harms to human health caused by the SARSCoV-2 virus, and the socio-environmental and economic impacts resulting from it, demand immediate and articulated responses, involving studies from different areas of knowledge. In this perspective, this article is the result of a study under development, of an exploratory, descriptive and analytical character, which aims to map the spatio-temporal distribution of confirmed cases and deaths registered in the state of Mato Grosso do Sul. Likewise, it aims to identify in the urban network, the spatial association between the levels of centrality and the 280 positive cases. Considering the period between epidemiological weeks 11 and 18 of 2020 , it can be said that, generally and preliminarily, contagion evolves from urban centers with higher levels of centrality to those with lower levels. On the other hand, heterarchical spatial interactions also contribute to understanding the beginning of contagion in centers with a lower hierarchical level. It is emphasized that the results can contribute to state health surveillance, offering subsidies for prioritizing places for actions, for monitoring and for studies that can identify socio-environmental risks and vulnerabilities.
\end{abstract}

Keywords: Health Geography. Urban network. COVID-19. Mato Grosso do Sul.

Recebido em: 10/05/2020

Aceito para publicação em: 21/05/2020. 


\section{INTRODUÇÃO}

"Enquanto todo mundo espera a cura do mal E a loucura finge que isso tudo é normal..."

(Dudu Falcão e Lenine)

Este texto é parte de um estudo em desenvolvimento, de caráter exploratório, descritivo e analítico, que tem como premissa dois objetivos basilares: apreender a distribuição espaço-temporal dos registros dos casos confirmados por SARS-CoV-2 e dos óbitos por este vírus no estado de Mato Grosso do Sul; e identificar a associação entre os níveis de centralidade urbana e dispersão espacial do vírus nesta unidade federada.

A COVID-19 tornou-se um desafio a ser enfrentado por vários países em todos os continentes. A complexidade dessa realidade aponta para a necessidade de pensá-la a partir de diferentes fatores, perspectivas e escalas analíticas, que vão desde escalas do mundo vivido até escalas do mundo concebido. Contudo, uma das premissas que não pode ser desconsiderada é a dos fluxos que configuram interações espaciais. Estas interações espaciais são diretamente afetadas pelo processo de densificação dos meios de comunicação e transporte, cada vez mais rápidos, expressando a complexidade da realidade geográfica atual, marcada por uma relação dialética entre fixos e fluxos. (SANTOS, 1997).

Os casos da COVID-19, que começaram a se manifestar nos grandes centros urbanos, já demonstram uma tendência efetiva à interiorização. Portanto, há, na abordagem do tema, uma asserção ou conteúdo eminentemente geográfico e que, dentre outros, leva a pensar o papel da rede urbana.

Segundo Corrêa (2010), a rede urbana pode ser entendida por um conjunto de centros que se articulam por meio de relações materiais e/ou imateriais, possibilitando e assegurando fluxos, circulação de informações, de pessoas, de capital, de serviços etc. O mesmo autor (2006) ainda alerta que a rede urbana é produto social. E, nesse sentido, traz um conteúdo que se dá a partir dela e que, ao mesmo tempo, a produz. Esse processo dialético configura as interações espaciais, conceito de relevância para a compreensão, tanto da estruturação da rede, quanto da sua dinâmica e funcionamento.

Em um sentido mais amplo, vale referenciar que as mutações genéticas são eventos naturais e cotidianos. Uma destas mutações gerou um novo coronavírus, com os primeiros casos registrados na cidade de Wuhan, na populosa província chinesa de Hubei (HUI et al., 2020).

O novo coronavírus, do gênero Betacoronavirus, foi identificado inicialmente pelo ano de origem como 2019-nCoV. Este vírus desenvolve, em uma parte dos seres humanos, a doença COVID-19 (coronavirus disease 2019). Este microrganismo "coroado" provoca, na espécie humana, uma síndrome respiratória aguda grave, motivo pelo qual foi renomeado pelo Comitê Internacional de Taxonomia de Vírus por SARS-CoV-2, sigla inglesa de severe acute respiratory syndrome coronavirus 2 (LAl et al., 2020). Doravante, se empregará o termo COVID-19, por ser mais popularizado no Brasil, tanto em documentos oficiais e midiáticos quanto em textos científicos.

Associado à alta densidade tecnológica e informacional para o mapeamento genético de novas espécies se tem, no final do século XX e no início do século XXI, o aumento na dinamicidade dos fluxos de pessoas, mercadorias, informações, etc. ocorre em múltiplas escalas, sobretudo entre as cidades globais. Tal dinamicidade imprime a velocidade da lógica de acumulação capitalista, que exige, na atual etapa de globalização, a escala financeira do trilhão de dólares para apreender os processos de produção, circulação, distribuição, especulação, concentração e centralização. Santos (1996) qualifica o espaço geográfico, inserido nesta lógica, de meio técnico-científico-informacional, que, por sua vez, é umas das condições para o que o mesmo autor (2001, p.19-20) caracterizou no capítulo "O mundo como é: a globalização como perversidade":

De fato, para a grande maior parte da humanidade a globalização está se impondo como uma fábrica de perversidades. O desemprego crescente torna-se crônico. A pobreza aumenta e as classes médias perdem em qualidade de vida. O salário médio tende a baixar. A fome e o desabrigo se generalizam em todos os continentes. Novas enfermidades como a SIDA se instalam e velhas doenças, supostamente extirpadas, fazem seu retorno triunfal. A mortalidade infantil permanece, a despeito dos progressos médicos e da informação. A educação de qualidade é cada vez mais inacessível. Alastram-se e aprofundam-se males 
espirituais e morais, como os egoísmos, os cinismos, a corrupção. A perversidade sistêmica que está na raiz dessa evolução negativa da humanidade tem relação com a adesão desenfreada aos comportamentos competitivos que atualmente caracterizam as ações hegemônicas. Todas essas mazelas são direta ou indiretamente imputáveis ao presente processo de globalização.

A emergência de saúde pública de importância internacional foi declarada pela Organização Mundial da Saúde em 30 de janeiro de 2020, decorrente do surto global da COVID-19 (WHO, 2020a). Nesta data, haviam ocorrido 170 óbitos, todos na China, que detinha a quase totalidade dos 7.834 casos confirmados $(98,75 \%)$. Estes números, que trazem em cada unidade uma pessoa e, respectivamente, todas as relações sociais de cada uma delas, foram atualizados posteriormente pelo governo chinês, ampliando as tensões geopolíticas nos meses subsequentes, principalmente entre os governos estadunidense e chinês. Ainda na reunião em que ocorreu esta declaração, foram realizadas sete recomendações, das quais a primeira é questionável, por afirmar que "não há razão para implementar medidas que impeçam desnecessariamente o comércio internacional e as viagens. A OMS não recomenda limitar o comércio ou a circulação de pessoas" (WHO, 2020a).

Para não diminuir o ritmo de crescimento econômico, o manejo dessa emergência na escala internacional não foi devidamente realizado, mesmo quando na segunda recomendação da OMS deixava evidente que os sistemas públicos de saúde não são robustos em dezenas de países latinoamericanos, africanos, do oriente médio ou que se encontram em processo de desfinanciamento por políticas neoliberais. Nesta complexa conjuntura internacional, as correlações de forças no Brasil possibilitaram, em menos de uma semana, a declaração de emergência em saúde pública nacional, por meio da Portaria n. 188/GM/MS, de 4 de fevereiro de 2020.

A pandemia da COVID-19 somente foi decretada pela Organização Mundial de Saúde em 11 de março de 2020 (WHO, 2020b), quando já havia 118.319 casos confirmados e o registro de 4.292 óbitos. Se considerar que a testagem é realizada na maioria dos países apenas nos casos sintomáticos, ou seja, em menos de $20 \%$ das pessoas contagiadas; que a disponibilidade de testes é baixa, devido as disputas entre os países e os custos financeiros deste produto raro; e, que o teste RT-PCR, conforme nota técnica publicada pela Sociedade Brasileira de Análises Clínicas, apesar de ter o melhor nível de detecção para o SARS-CoV2, possuí sensibilidade para as diferentes amostras testadas de apenas $63 \%$, quando realizado através do método de swab nasal (SBAC, 2020), já se percebe o alto nível de subnotificação, ou seja, a quantidade de pessoas infectadas é muito maior do que a dimensionada pelos casos confirmados pelos testes disponíveis. Outros testes possuem níveis ainda mais significativos de resultados falsos positivos e falsos negativos, gerando dados que não traduzem a realidade sanitária analisada. A falta de informações robustas aumenta as pressões sobre gestores, trabalhadores e usuários dos sistemas públicos de saúde e limitam as possibilidades de respostas mais eficientes e eficazes, como revela o atual cenário brasileiro e o de países do "Norte".

Após 75 dias do primeiro caso confirmado no país, dia 10 de maio de 2020, já se registraram 10.627 óbitos e 155.939 confirmações de COVID-19, conforme dados do Ministério da Saúde, disponíveis através do Painel Coronavírus (BRASIL, 2020). Números crescentes e superiores ao estimado por grande empresário do setor alimentício, ao afirmar que o país "não pode parar por 5 ou 7 mil mortes" (BAND, 2000). Postura polêmica que não contribui para aumentar a sensibilidade de parte da população a aderir a medidas preventivas, funcionando como um limitador no enfrentamento à pandemia. Esse também foi o caso da comparação, feita pelo presidente da República Federativa do Brasil, com "uma gripezinha ou resfriadinho", em pronunciamento veiculado na televisão em 24 de março (BBC, 2020). Com o discurso de priorizar a economia, o presidente tenta combater o distanciamento do convívio social, uma estratégia importante para conter o surto epidêmico e evitar o colapso do Sistema Único de Saúde (SUS).

Em 19 de março, o Decreto n. 15.396 de Mato Grosso do Sul declarou emergência em razão da pandemia, uma semana após os dois primeiros casos confirmados e com incidência acumulada de 24 pessoas com o novo coronavírus. Destes, 22 na capital do estado, Campo Grande, um no município de Sidrolândia, limítrofe a capital e outro em Ponta Porã, cidade gêmea com a cidade paraguaia de Pedro Juan Caballero. Os dois casos do interior e os dois da capital tinham retornado recentemente de viagens a países europeus, as origens do contágio, e 20 foram por contato com caso confirmado. 
No dia 7 de abril, o Ministério do Desenvolvimento Regional, através da Portaria n. 870/SNPDC/MDR, reconheceu o estado de calamidade pública no estado de Mato Grosso do Sul, quando este contava 108 registros de COVID-19, mais da metade na capital (54,63\%) e 49 distribuídos entre 11 municípios do interior, com destaques para três no sul do estado. Como já ficou evidente, a distribuição espacial dos casos confirmados não é homogênea, nem entre os continentes, nem entre os países ou mesmo entre os municípios de uma unidade federada. Este estudo inicia as análises a partir da descrição e comparação dos dados registrados entre os municípios e busca avançar na compreensão das relações entre estes casos e a rede urbana do estado, que sua vez se liga a Grande Metrópole Nacional, São Paulo (REGIC, 2008).

\section{PROCEDIMENTOS METODOLÓGICOS}

O recorte espacial é a unidade federada de Mato Grosso do Sul, sendo a unidade de análise o município, os 79 municípios sul-mato-grossenses. O recorte temporal do estudo será da $11^{\mathrm{a}}$ à $18^{\mathrm{a}}$ semana epidemiológica (SE), ou seja, entre os dias 08 de março e 02 de maio de 2020 , conforme Brasil (2020). Os dados são atualizados diariamente e consolidados nos boletins epidemiológicos, emitidos pela Direção de Vigilância em Saúde da Secretaria de Estado de Saúde, em conjunto com o Centro de Operações de Emergências, e se encontram disponíveis no sítio eletrônico oficial (MATO GROSSO DO SUL, 2020). Nestes boletins constam o município de residência, o sexo, a idade, a data de notificação, o local de deslocamento/contato, o tipo de teste que confirmou o resultado e o desfecho de cada caso (óbito, internação, isolamento domiciliar, finalizou a quarentena).

Por se tratar dos primeiros esforços de analisar a espacialização da COVID-19 para macroescala, aplicou-se o método de representação cartográfica das figuras geométricas proporcionais, como orienta a Semiologia Gráfica de Bertin (1973). Os níveis de centralidade e os níveis de ligação com os centros são dados do estudo Regiões de Influências das Cidades 2007, realizado pelo IBGE (2008), representados pelos métodos dos pontos e das linhas ordenadas. Os métodos de representações dos dados qualitativos foram utilizados para expressar em linhas as rodovias federais, com maiores fluxos no estado, e as rodovias estaduais (IBGE, 2017), além de localizar os demais núcleos urbanos que não foram representados por meio de pontos ordenados.

O IBGE publicitou os resultados preliminares da pesquisa Regiões de Influência das Cidades 2018, mais especificamente os resultados relativos a rede de cidades na área de saúde. $O$ intuito foi somar esforços no enfrentamento à pandemia da COVID-19, ao reconhecer o momento de grave crise de saúde pública. No entanto, os resultados preliminares para área da saúde do estudo do IBGE (2020) não serão utilizados neste estudo, por não tomarem as micro e macrorregiões de saúde como recortes espaciais. As urgências relacionadas aos agravos da síndrome respiratória aguda grave (SRAG) seguem os fluxos estabelecidos pelos comitês estaduais e macrorregionais de saúde, conforme o princípio da regionalização e hierarquização do SUS.

Os que buscam o cuidado na rede de assistência privada por agravos devido a esta SRAG, eventualmente, encontram estes serviços de média e alta complexidades em cidades com baixos níveis de centralidade. A limitação pode ser verificada na própria nota técnica, ao apontar que parte dos entrevistados não possuem formação na área de saúde nem atuam em serviços desta área e associam, para os deslocamentos para os serviços de saúde de alta complexidade tecnológica, que "as cidades procuradas pela população para tratamento de câncer e cirurgias complexas" (IBGE, 2020, p. 11)

Os dados registrados de casos confirmados de COVID-19, aqui explorados por meio das representações cartográficas, foram produzidos pela coleta de 3.022 testes, notificados no período do recorte temporal deste estudo. A maioria dos 280 testes com resultados positivos foi realizada por RT-PCR $(82,50 \%)$, no contexto de agravos à saúde de pessoas que demandaram a assistência no SUS ou na rede suplementar. A mortalidade registrada se refere às pessoas que foram a óbito e tinham o teste de confirmação da contaminação pelo vírus estudado. Os registros de óbitos por SRAG não especificas não fizeram parte desta análise, mas devem ser investigados em novos estudos para se compreender melhor o real impacto da mortalidade por esta causa específica. Destes 280 casos confirmados, quase a metade refere-se a pessoas do sexo masculino $(51,07 \%)$ e a maioria no ciclo de vida adulto, compreendida entre os 18 e 59 anos $(78,57 \%)$; seguida por idosos $(17,50 \%)$, grupo de maior risco apontado por estudos em diversos países (HUI et al., 2020; LAl et al., 2020); e, de crianças e adolescentes (3,93\%). 
Outro método cartográfico que permite analisar a relação entre os diferentes níveis de centralidade da rede urbana e a dispersão espacial da COVID-19 é a sobreposição dos fluxos entre os centros da rede e as áreas de influência e a ocorrência do primeiro caso para os municípios com registros, acumulados em um ponto por município, situado no centroide do distrito sede. A partir da modelagem geoestatística, aplicando o método de ponderação do inverso das distâncias (IDW), com peso 3 e suavização com fator 0.3 para 79 pontos, correspondente aos municípios sul-mato-grossenses, foi possível gerar uma representação cartográfica que facilita a identificação das tendências de dispersão. Para um primeiro aprofundamento sobre a teoria e a análise da difusão espacial, sugerese o estudo de Catão (2016).

O IDW (Inverse Distance Weighting) é uma técnica de interpolação espacial que estima o valor de um atributo em locais não amostrados, a partir dos valores dos pontos amostrados em uma área. Esta técnica parte da noção de espaço isotrópico, uma das limitações deste tipo de modelagem, mas que pode ser complementado por outros planos de informações georreferenciados, contribuindo assim para aplicação do raciocínio geográfico em análises de sistemas de objetos e sistemas de ações, dos fixos e dos fluxos (SANTOS, 1997). O IDW, aplica de forma direta a Primeira Lei da Geografia, segundo a qual, de acordo com Tobler, todas "coisas estão relacionadas entre si, mas as mais próximas estão mais relacionadas que as mais distantes" (LONGLEY et al., 2013, p.77). A partir de uma amostragem espacial significativa em uma área, é possível criar uma superfície com valores preditivos, que permite uma interpretação preliminar.

Tais métodos e técnicas validadas cientificamente são ferramentas que contribuem para um primeiro nível de abstração da complexidade inerente ao espaço geográfico, cada vez mais denso, dinâmico e marcado pelo "imperativo da fluidez".

O desafio de aprofundar a compreensão da realidade requisita métodos e técnicas que permitem identificar e representar a diferenciação do espaço geográfico por outras linguagens, como a representação cartográfica, que privilegia a perspectiva vertical e amplia o potencial analítico, ao possibilitar novas concepções e representações do espaço geográfico, assim como a tomada de decisões, quer na escala do indivíduo quer na escala social, é importante para administração privada e imprescindível na gestão pública. Nos arsenais teórico-metodológicos os diferentes métodos e técnicas ainda devem ser considerados, uma vez que somente a complementariedade das abordagens possibilitaram compreensões mais aprofundadas da totalidade.

\section{DISTRIBUIÇÃO ESPACIAL DA COVID-19 NA REDE URBANA SUL-MATO-GROSSENSE}

A análise da distribuição espaço-temporal a partir das formas e seus respectivos conteúdos permite identificar, na estrutura espacial, os processos sociais que elucidam a compreensão de fenômenos complexos, como corrobora Santos (2012 [1985], p. 77) ao afirmar que "a evolução que marca a etapa do processo de trabalho e das relações sociais marca, também, as mudanças verificadas no espaço geográfico, tanto morfologicamente, quanto do ponto de vista das funções e dos processos".

Partindo desta premissa, se busca, na análise da evolução espacial dos casos confirmados (Mapas 1 e 2), um primeiro esforço para apreender as estruturas espaciais que possibilitem compreender a dispersão espacial da COVID-19 no estado de Mato Grosso do Sul. As representações cartográficas expressam a incidência acumulada dos casos registrados por semana epidemiológica (SE), indicada em cada mapa pela data do último dia da SE.

Ao analisar a incidência acumulada dos casos confirmados no período da $11^{\mathrm{a}}$ à $18^{\mathrm{a}}$ semana epidemiológica, ou seja, o somatório de todos os casos registrados no período de 08 de março a 02 de maio de 2020, se evidenciam Campo Grande e Três Lagoas, com 142 (51\%) e 59 (21\%), respectivamente, conforme o Mapa 1. Este quadro expressa a situação da SE 18. Campo Grande é sede da capital estadual, com maior população do estado, 895.982 habitantes, conforme estimativa para o ano de 2019 (IBGE, 2020). Já Três Lagoas contabiliza a terceira maior população, com 121.388 habitantes. Juntos, somam também a maioria dos óbitos, 5 dos 9 casos.

Apesar da concentração de casos na capital ser maior do que a proporção populacional $(32,24 \%)$, Campo Grande concentra as conexões aeroviárias e rodoviárias do estado, e, por decorrência, tem a maior movimentação de passageiros. É nessa perspectiva que se compreende que o contágio pela COVID-19 na rede urbana ganha sentido à luz do conceito de interações espaciais. De acordo com Corrêa (2010, p. 79): 
"As interações espaciais devem ser vistas como parte integrante da existência (e reprodução) e do processo de transformação social e não como puros e simples deslocamentos de pessoas, mercadorias, capital e informação no espaço".

Mapa 1 - Espacialização dos casos confirmados da COVID-19 em Mato Grosso do Sul, 02 mai. 2020
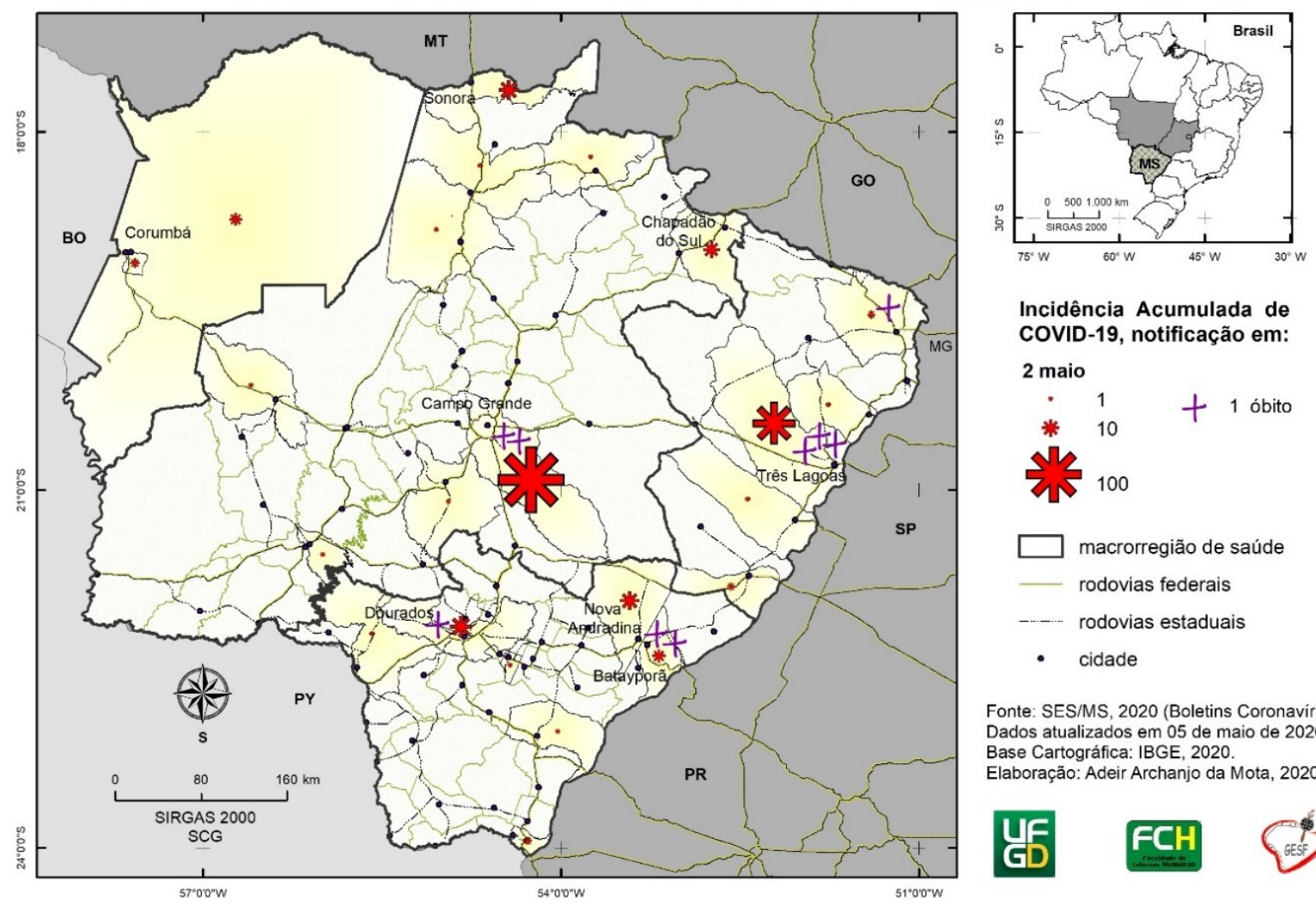

Incidência Acumulada de COVID-19, notificação em: 2 maio

$$
\begin{aligned}
& \text { * } 10+1 \text { óbito } \\
& \text { *2 } 10 \\
& \square \text { macrorregião de saúde } \\
& \text { - rodovias federais } \\
& \text { _...... rodovias estaduais } \\
& \text { - cidade }
\end{aligned}
$$

Fonte: SES/MS, 2020 (Boletins Coronavirus) Dados atualizados em 05 de maio de 2020. Base Cartográfica: IBGE, 2020.

Elaboração: Adeir Archanjo da Mota, 2020.

Além das expressivas quantidades absoluta e relativa, Campo Grande foi a primeira a registrar casos da COVID-19, em 12 de março, o que exigiu esforços para conter o surto no estado. Devido aos papéis que exerce, possui o maior nível de centralidade na rede urbana sul-mato-grossense (IBGE, 2008). Essa condição faz com que promova interações espaciais com todos os centros urbanos do estado, contribuindo para a disseminação de patologias infectocontagiosas, que se não controladas, podem gerar surtos epidêmicos.

Certamente as medidas implementadas nas SE 11 e 12, a exemplo do decreto da emergência de saúde pública no estado e dos decretos municipais expedidos por parte considerável dos municípios do estado, serviram de "freios" para disseminação do vírus. Uma hipótese forte para explicar o comportamento da curva nas três primeiras semanas se relaciona ao índice de distanciamento social, conforme os dados disponíveis no painel da Inloco (2020), no qual se pode observar o aumento de quase $35 \%$, no início de março, para a faixa de $50-60 \%$, na segunda quinzena deste mesmo mês.

Da mesma forma, as informações veiculadas pelas mídias, evidenciando o caos nos sistemas de saúde de países europeus, como da Itália e Espanha, também reforçaram a percepção dessa necessidade. 
Mapa 2 - Distribuição espaço-temporal dos casos da COVID-19 em Mato Grosso do Sul, 2020
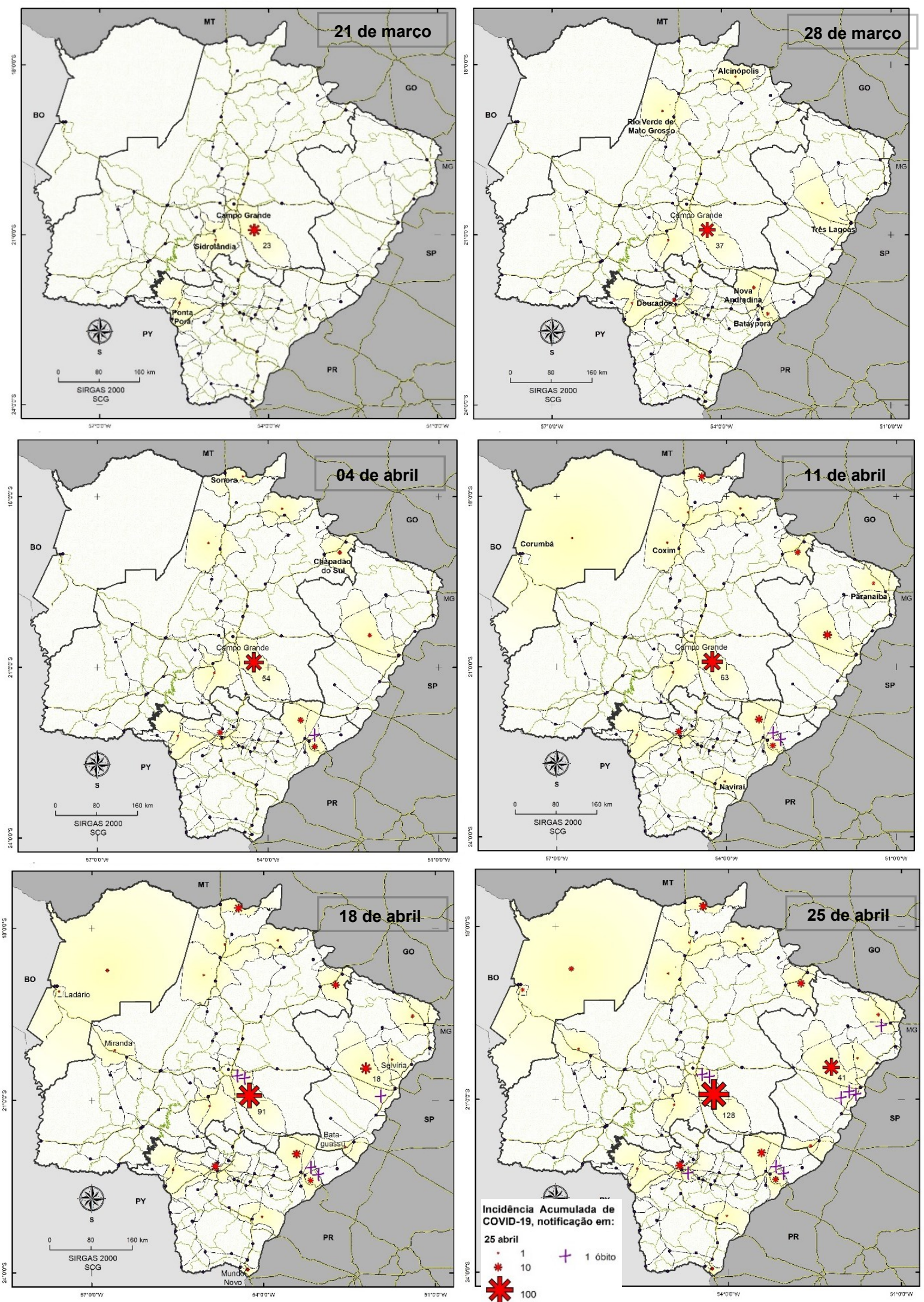

Fonte: Mato Grosso do Sul, 2020 (Boletins COVID-1y). Lados atualızados em 05 de maio de 2020. Base Cartográfica: IBGE, 2020, Elaboração: Adeir Archanjo da Mota, 2020. 
Quando se observa o Mapa 3, que apresenta a interpolação espaço-temporal do primeiro caso da COVID-19 por município sul-mato-grossense, é perceptível a relação direta entre a hierarquia da rede urbana do estado e a ordem cronológica do primeiro caso confirmado. Dentre os 79 centros urbanos do estado, Campo Grande, a único Centro Regional A, foi o único a ter 4 casos registrados na SE 11. Neste período, a quase totalidade foi registrada na área central do estado (Mapa 2). Nas duas semanas seguintes (12 e 13), dos 8 centros que registraram casos, um é Dourados, Capital Regional C, com a segunda maior população do estado; três são Centros de Zona A; e quatro são Centros Locais.

$\mathrm{Na}$ SE 13, os casos registrados em Batayporã, Nova Andradina e Dourados estão relacionados ao retorno de uma viajante da Europa, que após contatos com familiares e conhecidos, manifestou sintomas que a fez procurar os serviços de saúde nas três cidades mencionadas. Além da disseminação da doença entre pessoas próximas, ocorreu também a contaminação de profissionais de saúde, o que refletiu em considerável acréscimo nos casos registrados no sul-sudeste. Ainda relacionados a estes casos, ocorreram os dois primeiros óbitos pela COVID-19 no estado (Mapa 2). Uma particularidade deste caso foi o de evidenciar as interações espaciais heterárquicas (CATELAN, 2013), por ser um caso importado de outro continente, que após contagiar pessoas no centro local, promoveu a dispersão em Nova Andradina, um Centro de Zona A e, posteriormente, em uma Capital Regional C, Dourados.

Os primeiros casos registrados no extremo norte e no leste do estado ocorreram na SE 13, mas foi nas SE 14 e 15 que ficou evidente a alta incidência de casos, registrados em dois Centros de Zona $A$ (Corumbá e Naviraí), em três Centros de Zona B (Chapadão do Sul, Paranaíba e Coxim) e um Centro Local (Quadro 1). Este centro é Sonora, situado na divisa com Mato Grosso, na BR-163, um importante eixo de ligação entre a região Centro-Oeste com as regiões Norte, Sul e Sudeste do país. A situação geográfica privilegiada que ocupa na malha viária também a expõe mais à proliferação de doenças infectocontagiosas, nitidamente visível nos 13 casos registrados. Nessas semanas 14 e 15, o índice de distanciamento oscilou entre $60 \%$ e $40 \%$, em nítida queda no início de abril (INLOCO, 2020).

Quadro 1 - Nível de centralidade urbana, incidência e data do primeiro caso registrado da COVID-19 nos municípios sul-mato-grossenses, entre a $11^{\mathrm{a}}$ e a $18^{\mathrm{a}}$ semana epidemiológica

\begin{tabular}{|l|c|c|c|}
\hline \multicolumn{1}{|c|}{$\begin{array}{c}\text { Municípios } \\
\text { (com casos registrados) }\end{array}$} & $\begin{array}{c}\text { Primeiro Registro } \\
\text { da COVID-19 } \\
\text { (semana epidemiol.) }\end{array}$ & $\begin{array}{c}\text { Nível de Centralidade } \\
\text { Urbana } \\
\text { (REGIC 2007) }\end{array}$ & $\begin{array}{c}\text { Casos Registrados } \\
\text { nas SE 11-18 } \\
\text { (incidência acumulada) }\end{array}$ \\
\hline Campo Grande & 11 & Capital Regional A & 142 \\
\hline Sidrolândia & 12 & Centro Local & 1 \\
\hline Ponta Porã & 12 & Centro de Zona A & 1 \\
\hline Batayporã & 13 & Centro Local & 6 \\
\hline Dourados & 13 & Capital Regional C & 15 \\
\hline Rio Verde de Mato Grosso & 13 & Centro Local & 1 \\
\hline Três Lagoas & 13 & Centro de Zona A & 59 \\
\hline Nova Andradina & 13 & Centro de Zona A & 11 \\
\hline Alcinópolis & 13 & Centro Local & 1 \\
\hline Chapadão do Sul & 14 & Centro de Zona B & 9 \\
\hline Sonora & 14 & Centro Local & 13 \\
\hline Corumbá & 15 & Centro de Zona A & 5 \\
\hline Paranaíba & 15 & Centro de Zona B & 2 \\
\hline Naviraí & 15 & Centro de Zona A & 1 \\
\hline Coxim & 15 & Centro de Zona B & 1 \\
\hline Mundo Novo & 16 & Centro de Zona A & 2 \\
\hline Miranda & 16 & Centro de Zona B & 1 \\
\hline Ladário & 16 & Centro Local & 3 \\
\hline Selvíria & 16 & Centro Local & 1 \\
\hline Paraíso das Águas & 16 & Centro Local & 1 \\
\hline Bataguassu & 16 & Centro de Zona B & 2 \\
\hline Brasilândia & 18 & Centro Local & 1 \\
\hline Guia Lopes da Laguna & 18 & Centro Local & 1 \\
\hline Fonal Mal & & \\
\hline
\end{tabular}

Fonte: Mato Grosso do Sul, 2020 (Boletins COVID-19); IBGE, 2008 (REGIC 2007); Org.: Os autores, 2020. 
Mapa 3 - Dispersão Espacial da COVID-19 e a Rede Urbana de Mato Grosso do Sul, da $11^{\mathrm{a}}$ à $18^{\mathrm{a}}$ semana epidemiológica de 2020

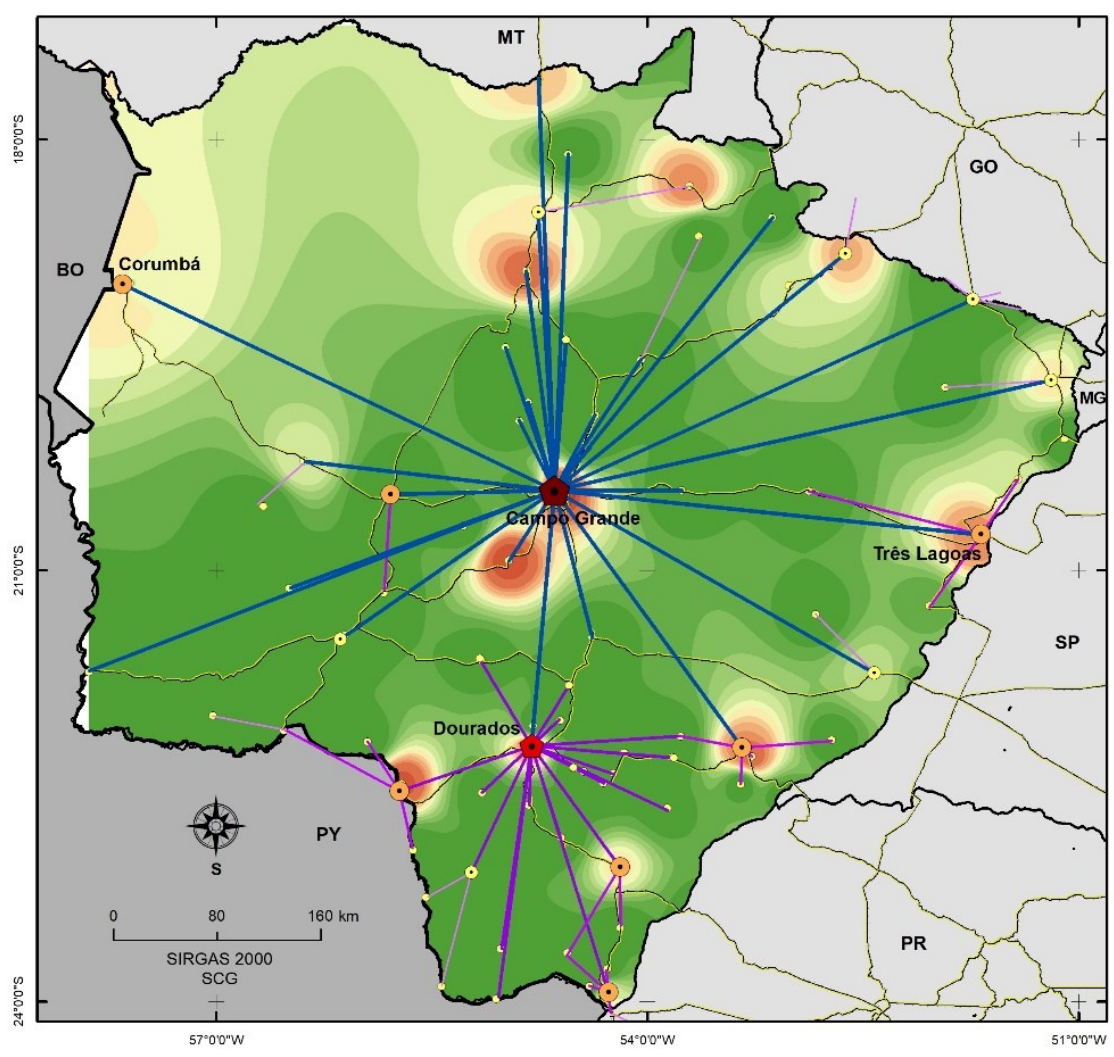

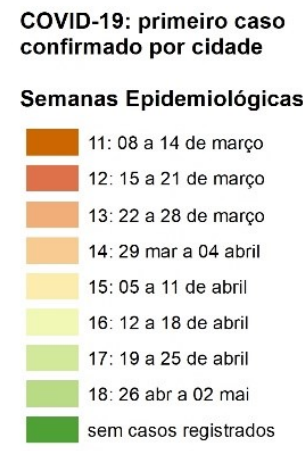

Rede Urbana de MS Nivel de Centralidade

- Capital Regional A

- Capital Regional C

- Centro de Zona A Centro de Zona B Centro Local

- Rodovias federais

Fonte: Mato Grosso do Sul, 2020; IBGE, 2008. (REGIC 2007) Base Cartográfica: IBGE, 2020 Elaboração: Adeir Archanjo da Mota, 2020.

Na SE 16 foram registrados os primeiros casos em 6 centros (Mapa 3), um Centro de Zona A, dois Centros de Zona B e três Centros Locais. O índice de distanciamento oscilou nesta semana entre $51 \%$ e $39 \%$ (INLOCO, 2020). Chama a atenção o processo de dispersão na região de influência de Três Lagoas, pelo registro de caso em Selvíria, quando esse centro urbano somava 18 casos e já apresentava caso sem identificação da origem do contágio. Isso corrobora com a análise de Camagni (1993), que destaca que tais relações ocorrem entre um ponto central e seu entorno.

A semana 17 não registrou casos em novos locais, acumulando 69 novos casos nos centros urbanos que já tinham registros, com destaque para Três Lagoas, que duplicou a quantidade de casos confirmados e foi o primeiro a somar três óbitos. Na SE 17, o índice de distanciamento ficou nos níveis da SE 16, conforme os dados da Inloco (2020). Já na SE 18, este índice decresceu ainda mais, registrando apenas $37 \%$ no dia 30 de abril, o que contribuiu para dinamizar a disseminação do vírus estudado, em especial os que não identificaram a origem do contágio.

Dentre os 19 centros urbanos que contam com nível de centralidade maior que a de centro local, apenas 5 não possuem registro da COVID-19, a saber: Aquidauana, um Centro de Zona A; e Amambai, Bela Vista, Camapuã, Cassilândia e Jardim, 5 Centros de Zona B, conforme a tipologia do estudo REGIC 2007 (IBGE, 2008). Estes centros urbanos precisam de melhor monitoramento, pois os níveis de interações espaciais a eles relacionados e os papéis que exercem em suas áreas de influência os tornam um tipo de fronteira para disseminação do vírus e demandam mais testagem e estudos.

A abordagem do espaço geográfico a partir da rede urbana, na análise da disseminação deste novo vírus, permite elucidar mais uma faceta da estrutura espacial, condicionante e condicionada pelas interações espaciais, que revelam a diferença dos lugares. Estas diferenças precisam ser mais bem compreendidas, a medida que também podem revelar desigualdades socioespaciais, daí urge a necessidade de novos estudos para identificar e garantir a assistência aos grupos de risco de 
desenvolverem as formas mais graves da COVID-19, assim como aos segmentos sociais em situação de vulnerabilidade socioambientais.

As opiniões e especulações sem embasamento científico também se colocam como importante desafio para o manejo dessa emergência, que já revela o esgotamento do sistema de saúde pública, com destaque para os serviços de alta complexidade. Este quadro, aliado a um baixo nível de distanciamento social, tem se desdobrado em algumas capitas do país no colapso local da rede de assistência à saúde, a exemplo do caso dramático de Manaus (AM).

\section{CONSIDERAÇÕES FINAIS}

Diante da pandemia que tem assolado diferentes países, a intensa mobilidade espacial, uma característica da globalização, é um desafio para o manejo de vírus com alto nível de transmissibilidade, como o SARS-CoV-2. A velocidade da dispersão pode ser reduzida com o distanciamento do convívio social, ou seja, a necessidade de desacelerar as relações em diferentes escalas geográficas, sobretudo e simultaneamente, nas escalas interurbana e intraurbana.

Contraditoriamente, também é no processo de globalização, marcada pelos intensos fluxos de pessoas e objetos, que se realiza a quase totalidade da produção de equipamentos de proteção individual, dos ventiladores mecânicos e de outros insumos que visam mitigar os agravos à saúde por este novo vírus.

Ao analisar a dispersão espacial da COVID-19 na rede urbana de Mato Grosso do Sul, considerando os dados registrados e cientes da elevada subnotificação, pode-se afirmar, de forma geral e preliminarmente, que o contágio evolui dos centros urbanos de maiores níveis de centralidade para os de menores níveis. Por outro lado, as interações espaciais heterárquicas também contribuem para compreender o início do contágio em centros de menor nível hierárquico.

Ressalta-se que os resultados podem contribuir com a vigilância em saúde estadual, oferecendo subsídios para a priorização de locais para ações, para o monitoramento e para estudos que possam identificar riscos e vulnerabilidades socioambientais.

Aponta-se ainda, a necessidade de considerar, em novos estudos, a análise da correlação dos indicadores socioambientais, demográficos, assistenciais, culturais, econômicos e sanitários com a velocidade da dispersão espacial, os níveis de incidência e de letalidade pela COVID-19. Além de ampliar o conhecimento dos impactos desta pandemia, estes estudos somam esforços para melhor compreensão da complexidade dos diferentes contextos geográficos.

Para continuar, reforça-se que a continuidade das reflexões acerca do tema evoca a solidariedade, a cooperação e a complementariedade, princípios que funcionam como uma bússola, no caminhar rumo à utopia que Santos $(2001$, p. 20) proclamou em "O mundo como pode ser: uma outra globalização".

\section{REFERÊNCIAS}

BAND. Confinamento vai matar mais do que o vírus, diz dono do Madero. Disponível em: https://noticias.band.uol.com.br/noticias/100000986148/confinamentovaimatarmaisdoqueovirusdizdon odomadero.html. Acesso em: 03 mai. 2020.

BBC. 'Gripezinha ou resfriadinho' e outras 7 frases controversas de líderes mundiais sobre o coronavírus. Disponível em: https://www.bbc.com/portuguese/internacional-52205918. Acesso em: 03 mai. 2020.

BERTIN, J. Sémiologie graphique: les diagrammes, les tréseaux, les cartes. Paris: Gauthier-Villars, 1973.

BRASIL. Ministério da Saúde. Painel Coronavírus. Disponível em: https://covid.saude.gov.br. Acesso em: 07 mai. 2020.

CAMAGNI, R. Economía urbana. Barcelona: Antonio Bosh, 1993.

CATÃO. R. C. Expansão e consolidação do complexo patogênico do dengue no estado de São Paulo: difusão espacial e barreiras geográficas. Tese (Doutorado em Geografia) - FCT, UNESP. Presidente Prudente, 2016. 
CATELAN, M. J. Heterarquia urbana: interações espaciais interescalares e cidades médias. São Paulo: Cultura Acadêmica, 2013.

CORRÊA, R. L. Trajetórias geográficas. Rio de Janeiro: Bertrand Brasil, 2010.

INLOCO. Mapa brasileiro da COVID-19. Disponível em: https://mapabrasileirodacovid.inloco.com.br. Acesso em: 9 mai. 2020.

INSTITUTO BRASILEIRO DE GEOGRAFIA E ESTATÍSTICA - IBGE. Ligações Rodoviárias e Hidroviárias 2016. Rio de Janeiro: IBGE, 2017.

INSTITUTO BRASILEIRO DE GEOGRAFIA E ESTATÍSTICA - IBGE. Regiões de influência das cidades 2007. Rio de Janeiro: IBGE, 2008.

INSTITUTO BRASILEIRO DE GEOGRAFIA E ESTATÍSTICA - IBGE. Nota Técnica - Pesquisa Regiões de Influência das Cidades 2018 - informações de deslocamentos para serviços de saúde. Disponível em: https://www.ibge.gov.br/geociencias/cartas-e-mapas/redes-geograficas/15798regioes-de-influencia-das-cidades.html?=\&t=sobre. Acesso em: 7 abr. 2020.

$\mathrm{HUI}, \mathrm{D}$. S. et al. The continuing 2019-nCoV epidemic threat of novel coronaviruses to global health The latest 2019 novel coronavirus outbreak in Wuhan, China. International journal of infectious diseases, v. 91, p. 264-266, 2020. Acesso em: 5 mar. 2020. https://doi.org/10.1016/i.ijid.2020.01.009

LAI, C. C.; SHIH, T. P.; KO, W. C.; TANG, H. J.; HSUEH, P. R. Severe acute respiratory syndrome coronavirus 2 (SARS-CoV-2) and coronavirus disease-2019 (COVID-19): The epidemic and the challenges. International Journal of Antimicrobial Agents, v. 55, n. 3, 2020. Acesso em: 15 abr. 2020. https://doi.org/10.1016/j.ijantimicag.2020.105924

LONGLEY, P.A.; GOODCHILD, M.F.; MAGUIRE, D.J.; RHIND, D.W. Sistemas e Ciência da Informação Geográfica. 3. ed. Bookman: Porto Alegre, 2013.

MATO GROSSO DO SUL. Secretaria de Estado de Saúde. Coronavírus CoVID-19. Boletins Epidemiológicos. Disponível em: https://www.vs.saude.ms.gov.br/Geral/vigilancia-saude/vigilanciaepidemiologica/boletim-epidemiologico/covid-19/. Acesso em: 05 mai. 2020a.

SANTOS, M. Espaço e Método. 5. ed. São Paulo: Edusp, 2012 [1985].

SANTOS, M. A Natureza do Espaço: Técnica e Tempo, Razão e Emoção. São Paulo: Hucitec, 1997.

SANTOS, M. Por uma outra globalização: do pensamento único à consciência universal. 6. ed. Rio de Janeiro: Record, 2001.

SOCIEDADE BRASILEIRA DE ANÁLISES CLÍNICAS - SBAC. Nota Técnica sobre a não detecção do SARS-CoV-2 por RT PCR em pacientes com COVID-19. Disponível em: http://www.sbac.org.br/blog/2020/03/27/nota-tecnica-sobre-a-nao-deteccao-do-sars-cov-2-por-rt-pcrem-pacientes-com-covid-19. Acesso em: 03 mar. 2020.

WORLD HEALTH ORGANIZATION - WHO. WHO Director-General's statement on IHR Emergency Committee on Novel Coronavirus (2019-nCoV). Disponível em: https://www.who.int/dg/speeches/detail/who-director-general-s-statement-on-ihr-emergencycommittee-on-novel-coronavirus-(2019-ncov). Acesso em: 30 jan. 2020a.

WORLD HEALTH ORGANIZATION - WHO. WHO Director-General's opening remarks at the media briefing on COVID-19 - 11 March 2020. Disponível em: https://www.who.int/dg/speeches/detail/who-director-general-s-opening-remarks-at-the-media-briefingon-covid-19---11-march-2020. Acesso em: 30 jan. 2020b. 